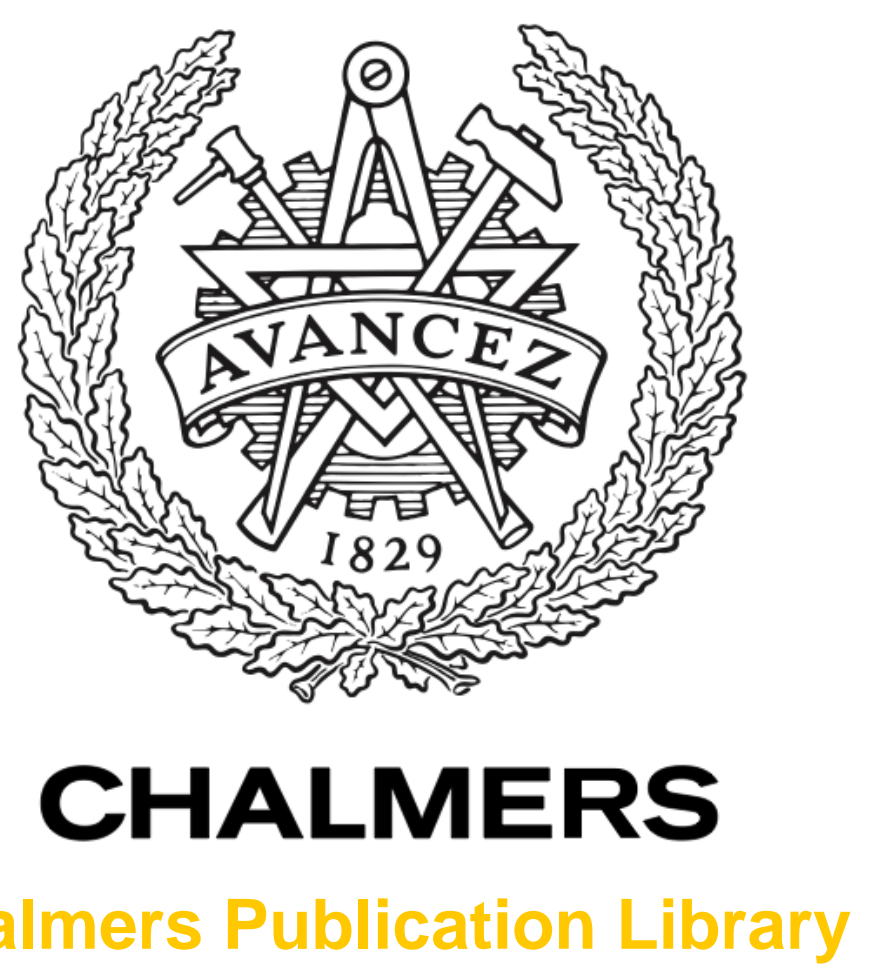

Keeping alive inter-organisational innovation through identity work and play

This document has been downloaded from Chalmers Publication Library (CPL). It is the author's version of a work that was accepted for publication in:

International Journal of Innovation Management (ISSN: 1363-9196)

Citation for the published paper:

Webb, J. (2017) "Keeping alive inter-organisational innovation through identity work and play". International Journal of Innovation Management, vol. 21(5),

Downloaded from: http://publications.lib.chalmers.se/publication/249764

Notice: Changes introduced as a result of publishing processes such as copy-editing and formatting may not be reflected in this document. For a definitive version of this work, please refer to the published source. Please note that access to the published version might require a subscription. 


\title{
KEEPING ALIVE INTER-ORGANISATIONAL INNOVATION THROUGH IDENTITY WORK AND PLAY
}

\author{
JANE WEBB \\ Department of Technology Management and Economics \\ Chalmers University of Technology, Vera Sandbergs allé 8 \\ 41296 Gothenburg, Sweden \\ janew@chalmers.se \\ Published
}

\begin{abstract}
This paper discusses how people draw on the strategic interests and motivations of their home organisations in negotiating the activities inter-organisational collaboration for innovation will include. Through presenting ethnographic snapshots of a case involving fifteen partner organisations, the paper explores how members of a coordinating group make sense of the possibilities and constraints for joint work. As they discuss new activities, they engage in identity work and identity play, simultaneously identifying with their home organisations and the meta-organisation. This finding challenges previous research assuming the importance of a coherent and stable collective identity for collaborative work. Instead the author suggests that innovation practitioners leave space for multiple objectives to emerge over time within joint activities in order to keep alive interorganisational innovation. The author calls for more research into how the interplay of organisational identities enables and constrains the practices of organising for interorganisational innovation.
\end{abstract}

Keywords: Inter-organisational innovation; collaborative innovation; open innovation; identity play; identity work; liminality; ethnography.

\section{Introduction}

Many innovation activities today take place inter-organisationally, with people coming together to participate in communities, ecosystems, platforms, consortia, alliances and networks. Despite this, researchers remain trapped in classic conceptualisations of boundaries between organisations, for example, conceptualising knowledge as flowing across boundaries, by inside-out, outside-in or coupled processes (Enkel et al., 2009). Taking the managing of knowledge flows as both the central purpose and outcome of collaboration, and knowledge as an object that 


\section{J. Webb}

is transferred from one owner to another across a boundary, contrasts with views that relate openness to sharing (Baldwin and Von Hippel, 2011). These views consider value in joint innovation activities not as taking the form of assets that can be traded, but as processes for exploring what can be done together. When engaging in an exploratory partnership, the explicit aim is to explore joint interests that are not known at the start but are instead shaped and revised along the way (Segrestin, 2005). Such views push towards more collective and shared conceptualisations of value, rather than value appropriation for a single organisation. This is perhaps especially true when the innovation activities are understood as connecting to societal challenges. However, benefiting from collaborative advantage is made even harder when objectives are not fixed and agreed by inter-organisational groups from the start (Huxham, 1996) and, this paper argues, when the purpose for collaboration is not conceived in terms of the value each organisation appropriates.

An assumption often underlying both practice and research is that sharing a clear vision and goals are part and parcel of inter-organisational innovation. There is an assumption of the importance of consensus between competing interests and motivations. The negotiation to agree a vision and goals with representatives of partner organisations would require 'dropping one's tools', Karl Weick's (1996) metaphor for being able to unlearn, adapt and be flexible. Weick intended this metaphor to speak of the potential for organisational renewal that can come through 'dropping tools'. One reason Weick (1996) provides for not being able to drop one's tools is identity, where an individual's work identity is bound up in her identification with the organisational identity. As Weick says, "the fusion of tools with identities means that under conditions of threat, it makes no more sense to drop one's tools than to drop one's pride" (1996, p. 308). Some people perceive an identity threat during work with colleagues from other organisations, wondering who they are in this new 'in-between' context, as they do their best to represent the home organisation. This paper discusses what it takes for people to drop the familiar tools stemming from their identification with the home organisation. It problematizes whether dropping one's tools is in fact desirable within interorganisational innovation. The author argues that keeping hold of the tools from identifying with one's home organisation can sometimes be what is needed to help the individual and their colleagues from other organisations to understand the possibilities and constraints of joint work.

People shape their identities from many possible sources of identification (Coupland and Brown, 2012; Moufahim et al., 2015; Watson, 2008) but this paper is particularly concerned with the interplay of organisational identities. The paper zooms in on entangled identities that become further entangled in the norms and imperatives of 'openness' and 'collaborativeness'. It focuses on how individuals 
shape their possibilities for action through the relational processes of everyday conversations (Cunliffe and Eriksen, 2011). Ultimately the aim of this paper is to explore the dynamics between the constraining and enabling aspects of organisational identities for people engaging in inter-organisational innovation. The paper argues that an emergent, dynamic collective organisational identity is central to energising and renewing joint work for innovation.

This paper provides a close-up of how one group of practitioners negotiate a vision for joint work between the organisations they represent, in the name of a collective organisation. The particular interest is a person's identification with both a home organisation and with the organisation-of-organisations. The guiding research question is: How do people navigate between organisational identities while discussing inter-organisational activities for innovation?

The next section situates this paper within research on inter-organisational innovation and introduces the concepts used as analytical lenses in this paper identity work and identity play. A description of the research design, methods and case follows, and then the analysis of how participants navigated between identities in the case. The discussion includes an illustration of the cycle of identity work and play in inter-organisational innovation. The final section summarises the implications and suggests directions for further research.

\section{Theoretical Background}

Understanding the processes of working together in emergent and situated innovation systems requires an interest in what enables the many people from different organisations to come together (Dougherty, 2017). Likewise, network types of inter-organisational collaboration deserve attention from researchers to complement the wealth of research focused on bilateral collaboration (Randhawa et al., 2016; West and Bogers, 2017). This is a typical research area that requires a crosslevel approach (Bogers et al., 2017) and where observation of interaction between people on the ground in their everyday work seems necessary. Researchers are increasingly interested in the 'human element' within inter-organisational innovation, recognising the dynamic relationship between organisational and individual spheres and arguing that this requires human-centric management principles (Salampasis and Mention, 2017). A fuller picture of organising within interorganisational networks or systems requires, then, an awareness of how people relate not just to their home organisations but also to the meta-organisation (Ahrne and Brunsson, 2005). A meta-organisation is one where the members are organisations, rather than individuals. It is an organisation-of-organisations or an association of organisations. 


\section{J. Webb}

\section{The give-and-take of inter-organisational innovation}

Since Chesbrough (2003) coined the term open innovation, researchers have keenly discussed forms of innovation in terms of openness, exploring whether openness is new (Trott and Hartmann, 2009); urging the importance of openness in innovation for societal benefits (Mention et al., 2016); as well as discussing the practicalities of being open and forms or modes of openness (Dahlander and Gann, 2010; Laursen and Salter, 2014, 2006; Lazzarotti and Manzini, 2009; Paasi et al., 2013; Zobel, 2017). Collaborating with other organisations for innovation expands the challenges inherent in all team-working (Du Chatenier et al., 2010). Within activities for inter-organisational innovation, the challenges of managing diversity, incentives, power, control and motivation take on new forms (Giannopoulou et al., 2011; Ollila and Elmquist, 2011; Paul et al., 2017; Sieg et al., 2010). One aspect that shapes the challenges stems from the dual allegiance for individuals who identify with both a home organisation and a meta-organisation. This is due to collaboration being so contingent on the contribution of people who are facing the burden of dealing with the uncertainty of their roles in an inter-organisational context (Husted and Michailova, 2010).

Researchers often bring to the fore the reciprocity, exchange or, put simply, the give-and-take, that is central to inter-organisational innovation as individuals try to deal with uncertainty. Indeed, many researchers emphasise give-and-take as what makes inter-organisational activities generative for innovation, although researchers sometimes reduce give-and-take to being only about balancing giving away knowledge with gaining as much as possible from a collaboration (Bogers, 2011). Others frame give-and-take as being about the relations between people, arguing that it is through the activities and relations that make up a community or network centred on exchange that the possibilities for learning from one another, and sources of innovation, emerge (Powell et al., 1996). A social network becomes the base for open innovation through people's behaviour and their expectations of reciprocal gift exchange (Dolfsma and Van Der Eijk, 2017). The explicit aim for a partnership may, in fact, be to shape and revise joint interests during encounters (Segrestin, 2005). The discussion of interests and matching of interests may be what give-and-take comes to mean for people working in such exploratory partnerships.

To understand more of how participating organisations may benefit from the creative outcome implicit in Huxham's (1993) idea of collaborative advantage, it is important to pay attention to the ways during joint work in which people explore opportunities, question assumptions and identify alternatives. Potential for collaborative advantage lies at the heart of why researchers and practitioners rally around the idea of 'open' forms of innovation. Any organisation, though, can face blind spots that may lead to inertia when the underlying assumptions of that 
organisation go unquestioned (Geiger and Antonacopoulou, 2009). This paper addresses the broad question of how to keep alive inter-organisational innovation by zooming in on everyday practices using an identities lens to explore aspects of the give-and-take between people as they navigate between organisational identities. The next section sets out the theoretical frames for this paper from research on identities in organisations.

\section{Working and playing with identities in innovation in-between organisations}

During inter-organisational innovation activities, people find themselves between organisations and must engage in sensemaking (Weick et al., 2005) about their work together. Making sense of such a context between organisational identifications and finding how to 'go on' with each other (Shotter, 1996), calls people to reconstruct their own identities in relation to the new work context and to each other. This experience likens that referred to by the concept of liminality, as an "experience of finding oneself at a boundary or in-between position, either spatially or temporally" (Thomassen, 2015). People working in inter-organisational innovation face liminal work experiences, continuing to represent a home organisation, but also identifying with a meta-organisation. However, unlike the highly-ritualised processes of transition originally associated with the concept of liminality, contemporary liminal work experiences such as those of interorganisational innovation are instead open-ended; with no clear transition to a new role in a social order; nor any established narratives to draw upon; nor, often, any guides to follow (Ibarra and Obodaru, 2016). Rather than look at the relationship between a person's actions in the inter-organisational context and her actions in other contexts, this paper concerns what happens when people interact in this new space between their home organisations, to organise as a meta-organisation, and how they cope with the uncertainty of innovation in-between organisations. The paper takes seriously what happens between people in the space in-between organisations and how such activities may be generative in keeping alive the collaboration.

To explore this, the paper turns to concepts from identities research. People engage in individual identity projects that involve a "continuous, precarious process of constructing a story of the self out of the discursive resources made available by the broader social context" (Moufahim et al., 2015, p. 93). One source of identification people draw upon to shape their sense of self are organisational identities. An organisational identity is a "specific type of purposeful collective identity" (Moufahim et al., 2015, p. 93), since managers and leaders often intervene to try to create a sense of belonging, commitment and loyalty. This paper draws on the concepts of 'identity work' and 'identity play' as ways to understand 


\section{J. Webb}

identification processes. Identity work refers to when individuals are "engaged in forming, repairing, maintaining, strengthening or revising the constructions that are productive of a sense of coherence and distinctiveness" (Sveningsson and Alvesson, 2003, p. 1165). While people engage in identity work continuously, there may be particular moments that "compel more concentrated identity work" (Sveningsson and Alvesson, 2003, p. 1165), such as those when people struggle with questions of: Who am I? Who are we? What do I/we stand for? The concept of identity play is intended to complement the concept of 'identity work' and is defined as individuals' engagement in provisional but active trial of possible selves (Ibarra and Petriglieri, 2010). Such processes of identity play appear to be experimental, linked to bringing about individual identity growth and the processes of creating new possibilities. Identity play is about exploring the threshold between what is now and what could be in the future.

Ibarra and Petriglieri, 2010 (2010, p. 19) suggest that the shift from exploring many identities to committing to one identity could denote the shift from identity play to identity work. While "people work at being certain things, [they] play at becoming others" (Ibarra and Petriglieri, 2010, p. 10). Ultimately identity work and play, for Ibarra and Petriglieri (2010), are distinguished in terms of their underlying purpose, place and process (Ibarra and Petriglieri, 2010). Fachin and Davel (2015) argue, however, that the concepts are not dichotomous, but instead interconnect during processes of identity experimentation such as those of career transition. This paper builds on this conceptualisation of the relationship between identity work and identity play. These twin concepts allow exploration of identity formation processes within the liminal context of inter-organisational innovation, particularly when what is agreed from the start is only the exploration of joint interests through collaboration, not the 'content' of the collaboration. Paying attention to the moments when individuals engage in 'identity work', and those when they engage in 'identity play', provides a way to understand how individuals navigate between organisational identities during their interaction with other participants and how these shifts affect joint innovation activities. Taking account of the many interests and motivations of the people involved in inter-organisational innovation, the meta-organisational identity could be compared to a network identity that shifts and is constantly remade as actors consider how they are alike and how they are different (Daskalaki, 2010). For such forms of collaboration to produce "innovative, synergistic solutions", participants must balance divergent stakeholder concerns (Hardy et al., 2005). This balancing work involves participants in shaping and being shaped by organisational identities during the course of their collaborative work.

While identities research is still an unexplored area when it comes to the phenomenon of inter-organisational innovation (Bogers et al., 2017; Randhawa et al., 2016), 
lenses from identities research may contribute to a more nuanced understanding of the practicalities of nourishing the relations between participating organisations. Understanding the dynamics of identity work and play in the liminal spaces of inter-organisational innovation helps innovation management researchers understand more about how people do in practice find a way to go on with each other. Lauritzen (2017) suggests that instead of seeking to resolve tensions in interorganisational innovation by developing capabilities to manage seeming paradoxes, people can find ways to make use of tensions related to power, identity and competence. Likewise, this paper uses the lenses of identity work and play in order to focus on how drawing on different sources of identification may be generative for innovation processes. Learning to live with the different interests and motivations for participation, and how these change over time, may instead be what is called for to keep alive inter-organisational innovation.

\section{Methods and Materials: Fieldwork with the Coordinators for SustainACity}

\section{Research design}

This research is from the initial period of longer-term, ethnographic fieldwork (Cunliffe, 2010; Garsten and Nyqvist, 2013). The case is a partnership of fifteen organisations testing and demonstrating products and services related to sustainable public transport. The research is intended to allow description of interactive, collaborative processes of joint value creation (Piller and West, 2014) and to provide the "force of example" (Flyvbjerg, 2006) that in-depth research provides. Yo-yo fieldwork (Wulff, 2002) was between several field sites and groups connected to the single case (Flyvbjerg, 2006; Siggelkow, 2007). During the first six months of research (April-September 2016), discussions about a new two-year phase of joint work took place. Such a period of goal-setting and transition heightened the ambiguity of the collective organisational identity, making it an appropriate time to observe identity formation processes in action (Hoholm and Araujo, 2011). Even when exploring inter-organisational practices of organising for innovation, most researchers focus on just one of the organisations involved (Bogers et al., 2017; Randhawa et al., 2016). Instead, this paper explores what happened for a meta-organisation, through observing the work of a coordinating group. With such a focus, the paper explores the everyday sensemaking of innovation practices as people put ideas of open innovation into practice, an area that merits further attention from researchers (Ollila and Yström, 2015; Remneland Wikhamn, 2016). 


\section{J. Webb}

\section{Fieldwork}

The main method was participant observation, totalling forty hours, at meetings or events, complemented by conversations. The paper draws particularly on observation at meetings of the coordinators for the overall partnership. Between the eight of them, the coordinators represented the fifteen partner organisations. I participated by encouraging reflection on working practices at the end of meetings. After observing the conversations and jotting down notes, I talked about what I had observed, to which the coordinators then added their own comments. This type of collaborative research (Shani et al., 2004) provides a check on the researcher's interpretation by giving space to hear the interpretations of others directly after observation of activities. This was a form of dialogical sensemaking between researcher and practitioners, to surface knowing-from-within and to develop socially useful knowledge (Cunliffe and Scaratti, 2017).

\section{Analysis}

As the material is from observation at working meetings, interpretation is based on 'operational data', rather than the 'presentational data' provided through interviews (Van Maanen, 1979). 'Real-time' ethnography intertwines analysis and observation as action unfolds (Hoholm and Araujo, 2011). At the same time as using in-the-field jottings to write up detailed fieldnotes after each day in the field, I wrote separate analytical in-process memos (Emerson et al., 2011). Later, I reviewed fieldnotes and in-process memos, as well as working documents and presentations used by the coordinators in meetings, coding the themes and incidents within these. This form of open coding gave way to more detailed integrative memos that linked themes, incidents and analysis (Emerson et al., 2011). A strong theme appearing across incidents was the contrast between when coordinators talked from "our perspective" of the home organisation and "our perspective" of the meta-organisation. As these incidents suggested the importance of identification with both the home organisation and the meta-organisation, I turned to identities research for concepts to further analyse the observed incidents. Using the complementary concepts of identity play and identity work as analytical lenses provided a way to characterise and discuss the interaction between the coordinators. In writing this paper to answer the question about navigating between organisational identities in inter-organisational innovation, I chose particular incidents that exemplified aspects of the observed identity work and identity play of the coordinators during the six months. The study suggests some general conclusions drawn from the interrelationship of the concepts of identity work and identity play in the particular case. 


\section{Case}

SustainACity is a partnership of fifteen organisations in a Northern European city. As the website for the partnership states, SustainACity is "an exciting cooperative venture bringing together industry, research and society in the development and testing of solutions for next-generation sustainable public transport”. Table 1 provides information about the partner organisations and the main groupings and representatives in which they met as partners in SustainACity during the research period. None of the partner organisations is responsible for directing SustainACity or any of the other participating organisations. Instead, representatives for each partner organisation must decide the work their organisations are interested in undertaking and how these projects can be organised alongside other projects under the umbrella of the meta-organisation of SustainACity.

\section{Analytical Snapshots of Navigating Between Identities}

This paper is based on material from a six-month period during which the coordinators of SustainACity discussed the next phase of their joint work or what they began to term SustainACity 2.0. The coordinators were making sense together of how to build on the collaborative work from one phase, celebrated and marked by the launch of a test electric bus route and indoor bus-stop, and decide what would come next. Individual coordinators moved back and forth between identification with their home organisation and with the meta-organisation during discussions, sometimes using 'we' when speaking from the perspective of their home organization and sometimes using 'we' to refer to SustainACity. At times individuals switched as quickly as from one sentence to the next, suggesting that organisational identifications were drawn on when finding a way to work with colleagues during liminal experiences. Sometimes one of the coordinators would implore others to work in the common interests of the meta-organisation. At other times, one of the coordinators would present the interests of their home organisation. Responses could be one of the coordinators making clear what was, and what was not, possible for the meta-organisation to engage in from the perspective of their home organisation, or an interest from one or more of the coordinators in exploring a new activity. Such new activities both had the potential to put into question the home organisation and meta-organisation.

The following snapshots from the coordinators' discussions show how the coordinators navigated between organisational identities to keep alive interorganisational innovation. The snapshots are presented in tables with key phrases in bold. The analytical discussion that follows each snapshot sets the snapshot in the wider context of other meetings, and teases out what the examples show of 
Table 1. Description of SustainACity.

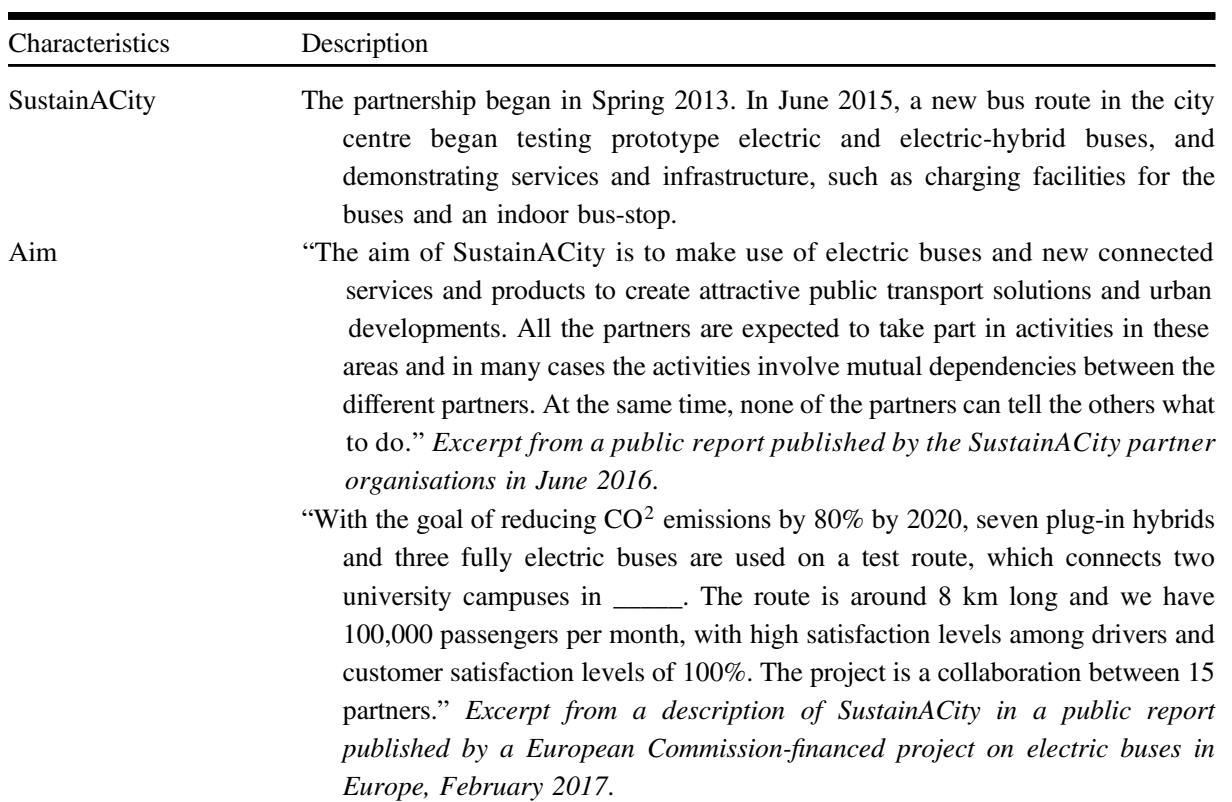

Fifteen partner organisations

Partnership organisation
TechUniversity, CityAuthority, RegionalGrowthAgency, RegionalAuthority, NationalEnergyAgency, CityAreaDevelopment, RegionalPublicTransportCo, WestSciencePark, EastSciencePark, AutomotiveCo, EnergyCo, CampusPropertyCo, AcademicPropertyCo, BusOperatorCo, TelecomCo*.

*Joined in June 2016

GreenTime.

Two consultants (Louise and Thelma) employed by RegionalGrowthAgency, TechUniversity, RegionalAuthority \& AutomotiveCo to act on behalf of all partners, overseeing and supporting activities when called upon by the steering group.

Coordinator Group.

Representatives for Automotive Co (Caroline)

TechUniversity (Neil), RegionalPublicTransportCo (Becky),

RegionalGrowthAgency (Johnny), CityAreaDevelopment (Jen) and TelecomCo (Peter)

with Louise \& Thelma from Green Time representing the other partner organisations.

Steering Group.

Representatives from AutomotiveCo, TechUniversity, RegionalPublicTransportCo, RegionalAuthority, CityAuthority and TelecomCo that meet six times per year.

Partner Group.

Senior representatives of the fifteen partner organisations that meet annually. In June 2016, the group confirmed TelecomCo as a new partner organization, and the focus areas for SustainACity up until June 2018. 
the dynamics between identity work and identity play when people experience moments of being between organisations during their work for inter-organisational innovation.

\section{We need to be closed to get anything done}

The SustainACity website lists a frequently asked question:

Is the cooperative venture open to other actors?

Yes, companies and research institutes that work with innovation and that can contribute to attractive and sustainable travel can join in, applying for financing via SustainACity.

Shaping a vision and goals for SustainACity for the coming years, engaged the coordinators in questions of: How open do we want to be? How open can we be? The coordinators moved between taking 'we' in these questions to mean SustainACity or to mean the home organization they represented. These were moments of identity play as the coordinators considered multiple possible future identities for SustainACity. Table 2 presents a snapshot that shows how one coordinator, Johnny, challenged the other coordinators. Johnny provokes his colleagues by pointing to the current phrasing of the goals for SustainACity 2.0 and challenging whether these are in line with the idea that companies and research institutes "that can contribute to attractive and sustainable travel can join in", as the website states.

The example suggests that Johnny was drawing on the collective identities mediating between his SustainACity colleagues' 'inward-looking', tied to the objectives of their home organisations, and ideas of a SustainACity more genuinely inviting to new partners. He challenges them to not be scared to bring in new partners and to think 'externally'.

During the coordinators' discussions on SustainACity 2.0, it was Johnny who pushed the group to remain aware of a goal to position the region "at the forefront of sustainable solutions and mobility". He repeatedly questioned how new organisations, in addition to the fifteen partner organisations, could find a way to work under the umbrella of SustainACity. Johnny was interested in how genuine the invitation to new partners was that the website set out. Drawing on the identification with his home organization, RegionalGrowthAgency, he pushed an agenda that suspended the coordinators in moments of identity play connected to the SustainACity identity. RegionalGrowthAgency works for "favourable conditions for trade and industry throughout the entire region by offering knowledge, contacts and arenas for collaboration". Johnny promoted the possibility that SustainACity could be an 'open' arena, while others responded with concerns about what 
Table 2. Snapshot: We need to be closed to get anything done.

It is a morning in April at the offices of EastSciencePark where Neil works. During a coordinator meeting when Louise, Caroline, Neil and Becky are present, Johnny, from RegionalGrowthAgency, brings up a conference he is arranging a few months later. He wants to know what the other coordinators think about a match-making system where delegates from supplier companies could book an appointment with representatives for SustainACity. The group start talking generally about how new organisations join SustainACity. Neil, from EastSciencePark but also representing TechUniversity, comments: "There's only a very small timeslot when the partners can actually be open to new partners". He continues: "There's no clear picture from the start of a sub-project that fits. Someone needs to shape it." Johnny tries to clarify that this is not his point. He says that he's talking instead "about use cases, quarterly updates, roadmaps....". He suggests posting these to the website so potential partners have a clearer idea about current activities and who to contact if they have a product or service to test. He argues: "We should not be scared of bringing in others." Neil counters that the problem is that this requires individual conversations with each person representing a potential new partner organisation. Louise, one of the GreenTime consultants, adds: "We need to be closed to get anything done." She says that it is "already enough with fifteen on the inside". Johnny says that he sees it more as being about the customer interface and helping companies see how they could join. Louise repeats a comment she made earlier in the meeting about how it is up to those responsible for each sub-project to decide who to involve. The meeting has already run past the time it was due to end and into lunchtime. Neil now abruptly wraps up the meeting without Johnny getting a clear answer on how the SustainACity partner organisations can make use of the conference.

The next day, Neil emails the group, saying that he has slept on the discussion about the conference: Due to the way cooperation in SustainACity is formed, makes it, in my eyes, not suited to taking in new partners in that way. Joining the partnership has so far been preceded by thorough dialogue and the sharing of both long-term intentions and own resources to take forward projects.

Caroline, from AutomotiveCo, is next to reply in the email thread. She agrees with Neil, and, referring to talks with colleagues internally at AutomotiveCo, comments:

It's hard to manage expectations from those who pitch. However, one could imagine a break-out session, earmarked for SustainACity, with workshops on various issues. The advantage would be that we are 'visible' and receive external input and contacts that we could then use, but without the expectation of continuation.

Neil replies just twenty minutes later to welcome Caroline's suggestion, with Johnny replying later that day to thank them both for their input.

While this closed down the question about the conference, at the meeting two weeks later Johnny again presses for 'openness'. Mid-way through the meeting, Louise clicks to a slide in her presentation with the wording of the SustainACity vision. "This is fixed," she says, adding that it is "hard to disagree with - it's basically talking about peace on earth." Johnny does pipe up though, commenting on how the goals are "quite internal, almost inward-looking". He adds: "They seem to represent what the partners get out. They do not feel very external." Caroline says: "It is for us. It is about giving us something that we can take to other cities." Johnny asks about how these goals show that: "We want to invite others to join." Louise tries to conclude the discussion, saying that the statements cannot be changed as the steering group has already approved them. Johnny says: "From the city's perspective, we need to think bigger. We need to make sure that people can ask themselves the question: How can we be a part of this arena?" 
'openness' entailed and whether it was a burden they could carry. As Louise suggested, getting things done required being closed. While all coordinators, at times, could be seen as acting to promote the interests of home organisations, Johnny used his identification with his home organisation to playfully push, purposefully provoking by using the SustainACity collective 'we' in response to Caroline using the collective 'we' of AutomotiveCo. This shows one aspect of the dynamics of identity work and play. While "people work at being certain things, [they] play at becoming others" (Ibarra and Petriglieri, 2010, p. 10). It seemed that Caroline was working hard to represent AutomotiveCo, defending that the goals were external as they were not just about one city, and refusing to 'drop her tools'. This kept alive the collaboration though by allowing Caroline to make clear to others what was possible for AutomotiveCo. While Johnny tried to provoke his colleagues to identity play for SustainACity, Caroline and others took turns to respond with identity work connected to their home organisations.

Since Chesbrough (2003) coined the term open innovation, researchers have keenly discussed forms of innovation in terms of openness. The snapshot presented shows that practical questions of openness in an exploratory partnership can engage participants in identity play, as they consider the extent to which they can live up to the imperative to be 'open'. As Ibarra and Obodaru (2016) link processes of identity play to bringing about individual identity growth, so too it appears from this case that identity play around the topic of openness helps participants in inter-organisational innovation explore what their joint work could be about, rather than the identity work of what it is about. The coordinators appeared to perceive a spectrum of openness on which they tried to place SustainACity, playing (up to a point) with the idea that their home organisation could also be a little more open and considering what openness meant for the home organisation.

\section{I don't know your world but I'm fascinated}

Various coordinators informally referred to what partnership in SustainACity entails as inviting partners to dance and in turn accepting offers to dance that they received. Another common metaphor was describing SustainACity to new people as a 'pot luck' dinner party, where participants brought a dish that could be shared with others and who then, in turn, could try the dishes that others brought. Louise and Thelma, the consultants who acted on behalf of all the partner organisations, purposefully shaped moments that allowed the coordinators to extend invitations to each other. These can be interpreted as moments of identity play. Each meeting, one of the coordinators had time to talk about the priorities for their home organisation. Table 3 presents an example, showing the 
Table 3. Snapshot: I don't know your world but I'm fascinated.

At the offices of RegionalPublicTransportCo, Becky is host for a coordinator meeting. It is Jen's first time meeting the rest of the group, newly having taken up a job at CityAreaDevelopment. Neil, Johnny, Louise and Caroline are present. About an hour into the meeting, it is time for Jen to present plans for the development of an old industrial area of the city. She starts with slides showing the wording for the vision for the new city area. Jen is noticeably cautious as she presents, repeatedly saying that this is just what she has been able to find out during her first two weeks. As she moves on to slides with detailed plans for a new neighbourhood in the area, showing where bus routes and bus-stops are planned to be, the group become more animated. Questions fly at Jen about dates and planning permission processes, but particularly about who is involved in each step and who ultimately has responsibility for decision-making. Jen goes up to the widescreen, mounted on the wall, to point to specific areas within the plan, tracing with her hand where the main bus lines are currently planned to go. Becky becomes a co-presenter of sorts alongside Jen, as she has been involved in RegionalPublicTransportCo's discussions with the Highway Agency about the transport infrastructure in the new area. The group talk about how ideas of locations for the bus-stops will change, with Becky commenting: "The bus-stops will move as bridges get built."

Johnny asks whether it would be possible to test automated buses on the empty land during the next few years before it is developed. Jen doesn't know but writes it down in her book as something to find out from her new colleagues. Johnny suggests that this might even connect to TelecomCo's interests when they join SustainACity. Becky talks about keeping the plans a little open to maintain the potential to be able to drive cars in the area, even though the intention is to design the area so that most residents and commuters will choose public transport. Having been quiet up until now, Neil comments to Jen: "I don't know your world at all but I'm fascinated". He says he has a lot of questions for her. Representing TechUniversity, he starts by asking Jen about how researchers could contribute to development of the neighbourhood. The back and forth between Neil and Jen continues for a while as the other coordinators listen and watch with interest.

Louise intervenes before anyone else can raise more questions. She emphasises that there is "a big opportunity out in the new neighbourhood to make sure that housing is not segregated, through how the traffic system is built out there." The group dives back into talking about political objectives in the region connected to innovation within the transport system and about how making activities part of SustainACity, allows those activities to become priorities for their home organisations. They all seems to agree that such explorative activities would otherwise not receive the attention and money. More questions are put to Jen about the numbers of households, office places, shops and schools. She emphasises that very few car parks are included. Louise says that "detailed plans are written in quite a flexible way these days. They can change." She suggests the group take a break, to digest all of this and then discuss how it connects to SustainACity. She wants the group to "create a joint picture of what we are going for". 
conversation after Jen introduced her work within city development, and so invited the other coordinators to shape activities together with CityAreaDevelopment, the organisation she represents.

The moments of such discussions appear to be a different aspect of identity play that yielded a different response to that of the earlier snapshot. Carefully slotted into the agendas by Louise and Thelma, these moments added momentum to the coordinators' work discussing SustainACity 2.0. They immersed the group temporarily in the priorities of one of the partner organisations, creating space to discuss joint activities within a prospective focus area for SustainACity 2.0. Presentations helped raise awareness of a new context, and clarified what had motivated one of the partner organisations to be a part of the meta-organisation. Importantly, it gave the coordinators representing different organisations, a new lens through which to look at how they and their home organisations could contribute to a focus area, such as city development, led by colleagues from one of their partner organisations.

In contrast to the other snapshot, this was a form of match-making of interests between the current SustainACity participating organisations, rather than consideration of new partners. These were invitations to joint activities among the fifteen organisations already "on the inside". Matching interests could mean that an organisation would get involved in areas of work previously not part of their strategy, such as traffic planning or the design of bus-stops. This could be described as co-design (Buur and Matthews, 2008), since the coordinators represented organisations that would usually consider each other as customers, suppliers, purchasers, contractors or competitors, rather than partners jointly responsible for an area of activity. Pragmatic agreements emerged for activities within focus areas where interests 'matched'. Such new relationships were interpreted as innovative for the organisations and as being made possible through the liminality that SustainACity offered to develop, test and demonstrate products and services in new ways. These were new activities that would otherwise not receive the attention and money if competing with other internal priorities of a home organisation, without the weight of the commitment to the partner organisations to engage in activities jointly as part of SustainACity.

This aspect of identity play was about being able to get to know someone else's 'world'. This contrasted to Johnny's recurring provocations about openness to new organisations, and was not so threatening to the identity work of striving to be a representative of a particular organisation. It seemed that coordinators felt able to 'drop their tools' momentarily and consider picking up new ones. Preparing for SustainACity 2.0 involved the partner organisations in thinking about how they could help each other in various activities. They were engaged in a social network where members expected reciprocal gift exchange (Dolfsma and Van Der Eijk, 


\section{J. Webb}

2017). As they exchanged insights into their worlds, they considered a changed identity for their home organisation as it became involved in new activities. At the same time, these activities breathed new air into the meta-organisation of SustainACity.

\section{The cycle of identity work and play in SustainACity}

The snapshots illustrate some incidents of how the coordinators of SustainACity navigated between organisational identities. One aspect of identity formation processes in the liminality of organising for inter-organisational innovation involves provocation and challenge, another aspect involves invitation. Provoking others by questioning the organisational identity of SustainACity, seemed to lead individual coordinators to respond with identity work where they strove to represent the perspectives of their home organisation and emphasise what was not possible. Inviting others by presenting the interests of one organisation, instead seemed to lead individual coordinators to respond with identity play where they strove to find ways to match interests in activities that were new to them and their home organisations. This meant that both invitation and provocation led to revisions to the SustainACity identity: provocation clarifying what was not possible, and invitation suggesting potential activities. Figure 1 illustrates the seeming cycle of identity work and play.

This cycle of identity work and play was between the identities of participating organisations and of the meta-organisation, and between opening up for new activities and closing down within the partnership. The coordinator asked themselves: Who are we? Who am I? What do we stand for? What do I stand for? They seemed to consider both their own home organisation and the meta-organisation of SustainACity. Arguably this ongoing cycle and the interplay of identities are

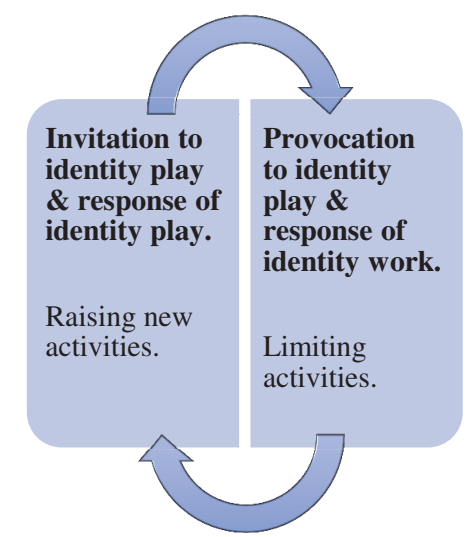

Fig. 1. Cycle of identity work and play in inter-organisational innovation. 
required to keep alive inter-organisational innovation, helping to avoid selflegitimising blind spots about the underlying principles of the collaboration, to consider new perspectives and to shape alternatives (Geiger and Antonacopoulou, 2009). It is through initiating joint activities that SustainACity is brought into being. Without the moments of identity play, the coordinators would lock themselves into the identity work connected to maintaining and strengthening the identities associated with the earlier phase of activities, rather than considering more broadly what activities SustainACity 2.0 could encompass. Identity play the provisional trying out of many possible selves — seems especially important as SustainACity is about testing and demonstrating new products and services. Without the responses of identity work, there would be ambiguity about what activities discussed during identity play would actually be undertaken in the name of SustainACity and about what constituted a manageable set of activities in which partner organisations would engage. There are shifts back and forth between using the familiar tools stemming from the identification with a home organisation, to becoming a little more familiar with the tools from another person's world. However, coordinators never totally dropped their tools and identified with SustainACity, the meta-organisation. Perhaps this was due to the ways that the SustainACity identity was so frequently subject to identity play.

\section{Discussion and Conclusions}

The paper contributes a tentative illustration of the dynamics of identity work and play in inter-organisational innovation. From the case presented in this paper, it seems that giving space to each organisation in an exploratory partnership to consider how their own interests match with one or more of the interests of other partner organisations is what renews collaboration for innovation. While partner organisations sign up to an overall vision agreed between participants, this can encompass many sub-objectives that to a greater or lesser extent involve the various partner organisations. Such organising has the feeling of a club, where members are continuously proposing activities, and inviting other members to join them, shifting between moments of identity play where they consider what they can do together and identity work where they strengthen the collective identity through pursuing a few activities raised during identity play. Invitations bring awareness to participating organisations of activities that could be of interest but which they otherwise would not have heard about outside of the opportunities to meet provided through the exploratory partnership. This allows organisational representatives to engage in activities that they would not otherwise have pursued. If participating organisations are to benefit from exploring opportunities through 


\section{J. Webb}

joint work, and so work towards the creative outcome implicit in Huxham's (1993) idea of collaborative advantage, so must organisations leave space for identity play within their joint work. While responses will indicate that sometimes the play is perceived as provocative and challenging, even these uncomfortable moments help keep alive the collaboration.

By focusing on the interaction between a group of people, this paper shows some aspects of how the work of individuals affect the processes of interorganisational innovation. There is a need for more research that helps deepen understandings of the complexity of what happens in practice. The small details of these practices have the power to shape how participation unfolds over time. While identity play is a relatively new concept, and identities research more generally is still an unexplored area when it comes to the phenomenon of interorganisational innovation (Bogers et al., 2017; Randhawa et al., 2016), such lenses may contribute to a more nuanced understanding of the practicalities of nourishing the relations between participating organisations, especially when there are no intermediaries with an explicit mandate to help participants manage paradoxes connected to identities (Lauritzen, 2017). The concept of identity play provides a perspective on how identities are shaped over time, remaining emergent, and appears particularly well-suited to the complex balancing of interests that occurs in practice as individuals experience the liminality of inter-organisational innovation, as partner organisations come and go, and as new activities are discussed. The concept presents a way of understanding the give-and-take required when organisations come together to shape complex innovation systems. As such systems are those now recognised as necessary to tackle societal challenges, further research into how identities at one level enable and constrain identities at other levels is warranted.

This paper is limited through only having looked at one case of an exploratory partnership of inter-organisational innovation and one where the explicit purpose is exploration of joint interests. Such a case means that identities are implicitly shaped and revised along the way. Further research in different contexts of interorganisational innovation would help refine how the concepts of identity play and identity work can provide a deeper understanding of the social relations between groups of individuals from participating organisations during innovationin-the-making.

\section{References}

Ahrne, G and N Brunsson (2005). Organizations and meta-organizations. Scandinavian Journal of Management, 21, 429-449. 
Baldwin, C and E Von Hippel (2011). Modeling a paradigm shift: From producer innovation to user and open collaborative innovation. Organization Science, 22, 1399-1417.

Bogers, M (2011). The open innovation paradox: Knowledge sharing and protection in R\&D collaborations. European Journal of Innovation Management, 14, 93-117.

Bogers, M, A-K Zobel, A Afuah, E Almirall, S Brunswicker, L Dahlander, L Frederiksen, A Gawer, M Gruber and S Haefliger (2017). The open innovation research landscape: Established perspectives and emerging themes across different levels of analysis. Industry and Innovation, 24, 8-40.

Buur, J and B Matthews (2008). Participatory innovation. International Journal of Innovation Management, 12, 255-273.

Chesbrough, HW (2003). Open Innovation: The New Imperative for Creating and Profiting from Technology. Boston: Harvard Business School Press.

Coupland, C and AD Brown (2012). Identities in action: Processes and outcomes. Scandinavian Journal of Management, 28, 1-4.

Cunliffe, AL (2010). Retelling tales of the field: In search of organizational ethnography 20 years on. Organizational Research Methods, 13, 224-239.

Cunliffe, AL and M Eriksen (2011). Relational leadership. Human Relations, 64, 1425-1449.

Cunliffe, AL and G Scaratti (2017). Embedding impact in engaged research: Developing socially useful knowledge through dialogical sensemaking. British Journal of Management, 28, 29-44.

Dahlander, L and DM Gann (2010). How open is innovation? Research Policy, 39, 699-709.

Daskalaki, M (2010). Building 'bonds' and 'bridges': Linking tie evolution and network identity in the creative industries. Organization Studies, 31, 1649-1666.

Dolfsma, W and R Van Der Eijk (2017). Behavioral foundations for open innovation: Knowledge gifts and social networks. Innovation: Organization \& Management, 19, 287-306.

Dougherty, D (2017). Organizing for innovation in complex innovation systems. Innovation: Organization \& Management, 19, 11-15.

Du Chatenier, E, JA Verstegen, HJ Biemans, M Mulder and OS Omta (2010). Identification of competencies for professionals in open innovation teams. $R \& D$ Management, 40, 271-280.

Emerson, RM, RI Fretz and LL Shaw (2011). Writing Ethnographic Fieldnotes. Chicago: University of Chicago Press.

Enkel, E, O Gassmann and H Chesbrough (2009). Open R\&D and open innovation: Exploring the phenomenon. $R \& D$ Management, 39, 311-316.

Fachin, FF and E Davel (2015). Reconciling contradictory paths: Identity play and work in a career transition. Journal of Organizational Change Management, 28, 369-392.

Flyvbjerg, B (2006). Five misunderstandings about case-study research. Qualitative Inquiry, 12, 219-245.

Garsten, C and A Nyqvist (eds.) (2013). Organisational Anthropology: Doing Ethnography in and Among Complex Organisations, London: Pluto Press.

Geiger, D and E Antonacopoulou (2009). Narratives and organizational dynamics: Exploring blind spots and organizational inertia. The Journal of Applied Behavioral Science, 45, 411-436. 
Giannopoulou, E, A Yström and S Ollila (2011). Turning open innovation into practice: Open innovation research through the lens of managers. International Journal of Innovation Management, 15, 505-524.

Hardy, C, TB Lawrence and D Grant (2005). Discourse and collaboration: The role of conversations and collective identity. Academy of Management Review, 30, 58-77.

Hoholm, T and L Araujo (2011). Studying innovation processes in real-time: The promises and challenges of ethnography. Industrial Marketing Management, 40, 933-939.

Husted, K and S Michailova (2010). Dual allegiance and knowledge sharing in inter-firm R\&D collaborations. Organizational Dynamics, 39, 37-47.

Huxham, C (1993). Pursuing collaborative advantage. Journal of the Operational Research Society, 44, 599-611.

Huxham, C. (ed.) (1996). Creating Collaborative Advantage, London: Sage.

Ibarra, H and O Obodaru (2016). Betwixt and between identities: Liminal experience in contemporary careers. Research in Organizational Behavior, 36, 47-64.

Ibarra, H and JL Petriglieri (2010). Identity work and play. Journal of Organizational Change Management, 23, 10-25.

Lauritzen, GD (2017). The role of innovation intermediaries in firm-innovation community collaboration: Navigating the membership paradox. Journal of Product Innovation Management, 34, 289-314.

Laursen, K and A Salter (2006). Open for innovation: The role of openness in explaining innovation performance among UK manufacturing firms. Strategic Management Journal, 27, 131-150.

Laursen, K and AJ Salter (2014). The paradox of openness: Appropriability, external search and collaboration. Research Policy, 43, 867-878.

Lazzarotti, V and R Manzini (2009). Different modes of open innovation: A theoretical framework and an empirical study. International Journal of Innovation Management, 13, 615-636.

Mention, A-L, JJP Ferreira and M Torkkeli (2016). Revisiting Openness: A must for society. Journal of Innovation Management, 4, 1-2.

Moufahim, M, P Reedy and M Humphreys (2015). The Vlaams Belang: The rhetoric of organizational identity. Organization Studies, 36, 91-111.

Ollila, S and M Elmquist (2011). Managing open innovation: Exploring challenges at the interfaces of an open innovation arena. Creativity and Innovation Management, 20, 273-283.

Ollila, S and A Yström (2015). 'Authoring' open innovation: The managerial practices of an open innovation director. In Research in Organizational Change and Development, ABR Shani and DA Noumair (Eds.). New York: Emerald Group Publishing Limited.

Paasi, J, K Valkokari and T Rantala (2013). Openness in developing inter-organizational innovation. Prometheus, 31, 107-124.

Paul, S, N Roijakkers and L Mortara (2017). How do human resource practices strengthen open innovation? An exploratory analysis. In Open Innovation: Unveiling the Power 
of the Human Element, D Salampasis and A-L Mention (Eds.). Singapore: World Scientific.

Piller, F and J West (2014). Firms, users, and innovation. In New Frontiers in Open Innovation, H Chesbrough, W Vanhaverbeke and J West (Eds.). Oxford: Oxford University Press.

Powell, WW, KW Koput and L Smith-Doerr (1996). Interorganizational collaboration and the locus of innovation: Networks of learning in biotechnology. Administrative Science Quarterly, 41, 116-145.

Randhawa, K, R Wilden and J Hohberger (2016). A bibliometric review of open innovation: Setting a research agenda. Journal of Product Innovation Management, 33, 750-772.

Remneland Wikhamn, B (2016). Open innovation as a facilitator for corporate exploration. International Journal of Innovation Management, forthcoming.

Salampasis, D and A-L Mention (eds.) (2017). Open Innovation: Unveiling the Power of the Human Element, Singapore: World Scientific.

Segrestin, B (2005). Partnering to explore: The Renault-Nissan Alliance as a forerunner of new cooperative patterns. Research Policy, 34, 657-672.

Shani, AB, A David and C Willson (2004). Collaborative research: Alternative roadmaps. In Collaborative Research in Organizations: Foundations for Learning, Change, and Theoretical Development, N Adler, AB Shani and A Styhre (Eds.). London, Thousand Oaks \& New Delhi: Sage Publications.

Shotter, J (1996). 'Now I can go on:' Wittgenstein and our embodied embeddedness in the 'Hurly-Burly'of life. Human Studies, 19, 385-407.

Sieg, JH, MW Wallin and G Von Krogh (2010). Managerial challenges in open innovation: A study of innovation intermediation in the chemical industry. $R \& D$ Management, 40, 281-291.

Siggelkow, N (2007). Persuasion with case studies. Academy of Management Journal, 50, 20-24.

Sveningsson, S and M Alvesson (2003). Managing managerial identities: Organizational fragmentation, discourse and identity struggle. Human Relations, 56, 1163-1193.

Thomassen, B (2015). Thinking with liminality. In Breaking Boundaries: Varieties of Liminality, A Horvath, B Thomassen and H Wydra (Eds.). New York: Berghahn.

Trott, P and D Hartmann (2009). Why 'open innovation' is old wine in new bottles. International Journal of Innovation Management, 13, 715-736.

Van Maanen, J (1979). The fact of fiction in organizational ethnography. Administrative Science Quarterly, 24, 539-550.

Watson, TJ (2008). Managing identity: Identity work, personal predicaments and structural circumstances. Organization, 15, 121-143.

Weick, KE (1996). Drop your tools: An allegory for organizational studies. Administrative Science Quarterly, 41, 301-313.

Weick, KE, KM Sutcliffe and D Obstfeld (2005). Organizing and the process of sensemaking. Organization Science, 16, 409-421. 


\section{J. Webb}

West, J and M Bogers (2017). Open innovation: Current status and research opportunities. Innovation: Organization \& Management, 19, 43-50.

Wulff, H (2002). Yo-yo fieldwork: Mobility and time in a multi-local study of dance in Ireland. Anthropological Journal on European Cultures, 11, 117-136.

Zobel, AK (2017). Benefiting from open innovation: A multidimensional model of absorptive capacity. Journal of Product Innovation Management, 34, 269-288. 